\title{
Evaluation of inexpensive blocking agents for ELISA in the detection of antibody in leprosy
}

\author{
J T DOUGLAS, $*$ Q X WU, $\dagger$ G P AGUSTIN $\ddagger$ \\ \& M G MADARANG $\S$ \\ *Department of Microbiology, University of Hawaii at Manoa; \\ $\dagger$ Department of Leprosy Research, Institute of Dermatology, \\ CAMS, Nanjing, PRC; $\ddagger$ Department of Microbiology, University of \\ Hawaii at Manoa; $\ddagger$ Leonard Wood Memorial Research Laboratory, \\ Cebu, Philippines
}

\section{Accepted for publication 12 June 1987}

\begin{abstract}
Summary In leprosy research, ELISA is currently being used to quantitate antibody concentrations in leprosy patients and their contacts. The advent of Mycobacterium leprae specific synthetic antigens has tremendously increased the sensitivity and specificity of the detection system being used. It allows researchers to monitor the effectiveness of chemotherapy and also permits early detection of lepromatous patients likely to spread the disease and those contacts who have contracted it. The use of this detection system has now gained popularity amongst researchers in various countries throughout the world. However, its use in some countries is still being hampered by availability and high costs of reagents, particularly, blocking agents. We compared 5 blocking agents commonly used and found $10 \%$ skimmed milk or nonfat dry milk to be the most suitable. It is as effective a blocking agent as those popularly used. It did not adversely affect the pattern of the ELISA response expected of high and moderate reacting sera. It is relatively inexpensive compared to bovine serum albumin (BSA) or normal goat serum (NGS), readily available (it can be purchased at local grocery stores), stable at room temperature and very simple to prepare.
\end{abstract}

\section{Introduction}

An important problem in the epidemiologic study of leprosy is the lack of reliable technology for detecting subclinical infections in patients infected with Mycobacterium leprae and detecting the disease in early stages. It is well known that the FLA-ABS test first established by Abe ${ }^{1}$ was demonstrated as a tool for these purposes. ${ }^{2}$ Recently, however, a new, simple, rapid, sensitive and quantitative technology, enzyme-linked immunosorbent assay (ELISA), has been developed and is now widely used in the quantitation of humoral antibodies for both clinical and research applications. The ELISA is now being applied to leprosy serology and in addition to increased sensitivity, it avoids the subjective analysis associated with fluorescent antibody tests.

In some countries where both technology and resources are limited, the transfer of this 
technology has met some difficulties. One problem encountered in the beginning was the quality of water used in sensitive assays. It was found that glass distilled water was a requirement. ${ }^{3}$ Another problem is the availability and cost-effectiveness of blocking agents. At present, some countries that are using the ELISA technology need to purchase their blocking agents from foreign suppliers because known, effective, pre-tested blocking agents are not available locally. Such long distance transactions are not only cumbersome but also time consuming. It may take as long as 6 months before a shipment is received, making it difficult to anticipate when the next order should be placed.

Another major obstacle is the cost of these blocking agents. Some, for example BSA (bovine serum albumin) can cost as much as US\$797.00 per $\mathrm{kg}$, plus shipping and handling. This can be a major problem for laboratories operating on a very limited budget. In this article, we compare the efficacy and cost of different blocking agents and discuss their advantages and disadvantages for use in countries where availability of reagent grade chemicals is limited.

\section{Materials and methods}

SERA

Leprosy patients were clinically and histologically classified according to the Ridley-Jopling scale. ${ }^{4}$ The sera were obtained from LWM laboratory in Cebu, Philippines and stored in aliquots at $-70^{\circ} \mathrm{C}$ until used. The lepromatous (high and moderate reactors) and normal sera were diluted $1: 1000$ in appropriate blocking agents.

\section{ANTIGEN}

ND-O-BSA (synthetic disaccharide containing neo-glycoconjugate), was kindly provided by $\mathrm{Dr}$ Brennan (Colorado State University, Fort Collins) under NIH contract. ${ }^{6}$ This antigen was diluted to a concentration of $0 \cdot 1 \mu \mathrm{g} / \mathrm{ml}$ with a volatile buffer, $0 \cdot 01 \mathrm{M}$ ammonium acetate-carbonate, $\mathrm{pH} 8 \cdot 2 .^{7}$

\section{CONJUGATE}

Peroxidase conjugated goat antihuman IgM (mu-chain specific, Cappel Laboratories) was diluted $1: 6000$ in appropriate blocking agents.

\section{SUBSTRATE}

O-phenylenediamine $0 \cdot 04 \%$ in citrate buffer $(\mathrm{pH} 5 \cdot 0)$ 0.003\% hydrogen peroxide.

\section{BLOCKING AGENTS}

$5 \%$ and $10 \%$ bovine serum albumin (BSA, w/v), $10 \%$ crude egg albumin (EAC, w/v) filtered, $10 \%$ skimmed milk or nonfat dry milk (SM, w/v), $10 \%$ normal goat serum (NGS, v/v) $10 \%$ and $20 \%$ egg white albumin (EA, v/v) filtered, all diluted in PBSTW20 (phosphate buffered saline with $0 \cdot 1 \%$ Tween 20) $\mathrm{pH} 7 \cdot 4$. All are prepared fresh daily and discarded after use to prevent bacterial contamination.

\section{TEST}

The procedure for ELISA was conducted in the following manner:

1 Coating plates. Add $50 \mu \mathrm{l}$ of prepared ND-O-BSA into each well. Incubate plates $14-18 \mathrm{~h}$ at $37^{\circ} \mathrm{C}$. 
2 Blocking. Prior to blocking, add $100 \mu$ l of PBSTW20 to each well and soak for $15 \mathrm{~min}$, then wash plates 3 times to remove unbound antigen. Add $100 \mu \mathrm{l}$ of appropriate blocking agent into each well (skip first column for blank). Incubate plates for $1 \mathrm{~h}$ at $37^{\circ} \mathrm{C}$.

3 First antibody reaction. Aspirate off the blocking agent from each plate and add $50 \mu \mathrm{l}$ of diluted sera in duplicate wells. Save the last row for controls and conjugate background. Incubate at $37^{\circ} \mathrm{C}$ water bath for $1 \mathrm{~h}$, then wash plates 3 times.

4 Second antibody reaction. Add $50 \mu$ l of diluted conjugate into each well except blank column. Incubate at $37^{\circ} \mathrm{C}$ for $45 \mathrm{~min}$. After incubation, aspirate off conjugate, soak plates for $3 \mathrm{~min}$, then wash 3 times.

5 Colour development. Add $50 \mu \mathrm{l}$ of OPD solution to each well and incubate plates at $37^{\circ} \mathrm{C}$ water bath for $20 \mathrm{~min}$. Stop reaction by adding $50 \mu \mathrm{l}$ of $2 \cdot 5 \mathrm{~N}$ sulphuric acid. Mix well. Read absorbance at $492 \mathrm{~nm}$.

\section{Results}

\section{COMPARATIVE RESULTS OF VARIOUS BLOCKING AGENTS}

Sera were routinely diluted $1: 1000$ to permit evaluation of high reacting lepromatous sera. The background levels of normal sera did not vary significantly at dilutions ranging from 1:500 to $1: 1000$.

It can be seen in Table 1 that both $10 \%$ BSA and $20 \%$ EAC, blocked the least. Normal sera were reading above $1 \cdot 0(\mathrm{~A})$. Even with the moderate reactors, there were still readings above $2 \cdot 0(\mathrm{~A})$. The high concentration of these two blocking agents prevented them from blocking efficiently. The same two blocking agents at a lower concentration blocked better. It was observed that the high concentration of albumin (protein) resulted in the production of large bubbles in this viscous solution. These bubbles obstruct the critical contact necessary between the blocking agent and the

Table 1. Comparative blocking efficiency of blocking agents

\begin{tabular}{|c|c|c|c|c|c|c|c|c|}
\hline \multirow{2}{*}{$\begin{array}{c}\text { Sera } \\
\text { No. }\end{array}$} & \multicolumn{8}{|c|}{ Blocking agents* } \\
\hline & $5 \%$ BSA & $10 \%$ BSA & $10 \%$ NGS & $10 \% \mathrm{EA}$ & $20 \% \mathrm{EA}$ & $10 \% \mathrm{EAC}$ & $5 \% \mathrm{EAC}$ & $10 \% \mathrm{SM}$ \\
\hline \multicolumn{9}{|c|}{ High reactors } \\
\hline 1 & $1.63 \dagger$ & $1 \cdot 61$ & $1 \cdot 73$ & $2 \cdot 10$ & 1.69 & 1.47 & $1 \cdot 39$ & $1 \cdot 12$ \\
\hline 22 & $2 \cdot 46$ & $2 \cdot 20$ & $2 \cdot 40$ & $2 \cdot 65$ & $2 \cdot 14$ & $1 \cdot 56$ & 1.66 & 1.95 \\
\hline 95 & $2 \cdot 65$ & $2 \cdot 19$ & $2 \cdot 44$ & $2 \cdot 77$ & $2 \cdot 41$ & 0.79 & $2 \cdot 05$ & 1.91 \\
\hline 180 & 1.81 & 1.73 & $1 \cdot 64$ & $1 \cdot 95$ & $1 \cdot 55$ & $1 \cdot 40$ & $0 \cdot 81$ & $0 \cdot 87$ \\
\hline \multicolumn{9}{|c|}{ Moderate reactors } \\
\hline 10 & $0 \cdot 37$ & 0.39 & $0 \cdot 36$ & $0 \cdot 37$ & $0 \cdot 26$ & $0 \cdot 25$ & $0 \cdot 23$ & $0 \cdot 16$ \\
\hline 23 & $0 \cdot 67$ & $2 \cdot 20$ & $0 \cdot 59$ & $0 \cdot 87$ & $2 \cdot 17$ & $0 \cdot 56$ & $0 \cdot 31$ & $0 \cdot 36$ \\
\hline 32 & $0 \cdot 31$ & $0 \cdot 26$ & $0 \cdot 24$ & $0 \cdot 31$ & 1.91 & $0 \cdot 12$ & $0 \cdot 29$ & $0 \cdot 11$ \\
\hline 35 & 0.52 & $1 \cdot 71$ & 0.42 & 0.55 & $1 \cdot 51$ & 0.40 & $0 \cdot 32$ & $0 \cdot 26$ \\
\hline \multicolumn{9}{|c|}{ Normal sera } \\
\hline 2 & $0 \cdot 10$ & $1 \cdot 38$ & 0.07 & $0 \cdot 11$ & $1 \cdot 19$ & 0.04 & $0 \cdot 17$ & $0 \cdot 04$ \\
\hline 3 & $0 \cdot 15$ & 1.79 & $0 \cdot 11$ & $0 \cdot 14$ & 1.58 & 0.07 & $0 \cdot 28$ & 0.06 \\
\hline 19 & $0 \cdot 13$ & 1.67 & 0.09 & $0 \cdot 13$ & 1.53 & 0.04 & $0 \cdot 32$ & 0.08 \\
\hline 33 & $0 \cdot 15$ & $0 \cdot 10$ & $0 \cdot 10$ & $0 \cdot 14$ & 0.08 & 0.05 & $0 \cdot 13$ & 0.05 \\
\hline
\end{tabular}

* BSA, bovine serum albumin; NGS, normal goat serum; EA, egg albumin, fresh; EAC, egg albumin, crude; SM, skimmed milk.

$\dagger$ Absorbance at $492 \mathrm{~nm}$. 
Table 2. Comparative absorbance range of the best blocking agents

\begin{tabular}{llll}
\hline Sera & $10 \%$ NGS$^{*}$ & $10 \%$ EAC & $10 \%$ SM \\
\hline High reactors $(n=12)$ & $2 \cdot 35 \pm 0.60 \dagger$ & $2 \cdot 16 \pm 0 \cdot 60$ & $2 \cdot 13 \pm 0 \cdot 60$ \\
Moderate reactors $(n=12)$ & $0 \cdot 32 \pm 0 \cdot 20$ & $0 \cdot 30 \pm 0 \cdot 20$ & $0 \cdot 27 \pm 0 \cdot 20$ \\
Normal sera $(n=12)$ & $0.08 \pm 0.05$ & $0 \cdot 08 \pm 0 \cdot 04$ & $0 \cdot 05 \pm 0 \cdot 02$ \\
\hline
\end{tabular}

* NGS, normal goat serum; EAC, egg albumin crude; SM, skimmed milk.

$\dagger$ Mean \pm range of ELISA absorbance at $492 \mathrm{~nm}$.

Table 3. Comparative expense of blocking agents*

\begin{tabular}{ll} 
Normal goat serum, mycoplasma tested, Gibco & $\$ 6 \cdot 22 / 100 \mathrm{ml}$ of $10 \%$ NGS \\
Bovine serum albumin $98-99 \%$ purity Sigma & $\$ 7 \cdot 97 / 100 \mathrm{ml}$ of $10 \%$ BSA \\
Egg albumin, crude dried egg white, Grade II, Sigma & $\$ 0 \cdot 20 / 100 \mathrm{ml}$ of $10 \%$ EAC \\
& $\$ 0 \cdot 03 / 100 \mathrm{ml}$ of $10 \%$ EA \\
Egg albumin, fresh egg white & $\$ 0 \cdot 05 / 100 \mathrm{ml}$ of $10 \% \mathrm{SM}$ \\
Skimmed milk, instant non-fat dry milk & \\
\hline
\end{tabular}

* Cost based on prices (US\$) in Honolulu, Hawaii (1986).

binding sites of the plates. The best blocking reagents were: 10\% NGS, 10\% EAC, 10\% SM. These resulted in low normal sera values without inhibiting the reactivity of the high and moderate reactors. Although the maximum range of reactivity decreased with the effectiveness of the blocking agents, the distinction between strong, moderate and normal sera became clearer. The 5\% BSA and $10 \%$ EA were not as efficient in blocking but did permit a clear distinction between high reactors, moderate reactors and normal sera.

\section{COMPARATIVE RANGE OF VALUES FOR THE BEST BLOCKING AGENTS}

The three most efficient blocking agents were selected based on the values observed in Table 1: 10\% NGS, $10 \%$ EAC, $10 \%$ SM. These reagents were compared with 36 sera as summarized in Table 2. Twelve samples were chosen for each group of high reacting, moderate reacting and normal sera. To avoid any plate variation, each group was loaded on one plate diluted in the three different blocking agents: column 1, blank; columns 2, 3, 4, 10\% NGS; columns 5, 6, 7, 10\% EAC; columns 8, 9, 10, $10 \%$ SM; columns 11, 12, conjugate. The same procedure was followed for the moderate and normal sera. As can be seen in Table 2, the lowest range for normal sera was found with $10 \% \mathrm{SM}$ without adversely decreasing the response of the moderate and high reactors.

\section{COMPARATIVE COST OF THE DIFFERENT BLOCKING AGENTS}

Table 3 compares the relative cost of the different blocking agents per $100 \mathrm{ml}$ of a $10 \%$ solution. Bovine serum albumin and normal goat serum are the two most expensive blocking agents costing US $\$ 7 \cdot 97 / 100 \mathrm{ml}$ and US $\$ 6 \cdot 22 / 100 \mathrm{ml}$ respectively. Skimmed milk and both fresh and crude egg albumin were found to be the least expensive: US $\$ 0.03$ to US $\$ 0.20$ per $100 \mathrm{ml}$. 
Table 4. Comparison of mean OD values obtained using $10 \%$ skimmed milk and $10 \%$ NGS

\begin{tabular}{lcccc}
\hline Type of Sera & \#Samples & $10 \%$ SM* $^{*}$ & $10 \%$ NGS $\dagger$ & Deviation $\ddagger$ \\
\hline Multibacillary§ & 31 & $0.52 \pm 0.57$ & $0.54 \pm 0.57$ & 0.03 \\
Paucibacillary & 32 & $0.05 \pm 0.04$ & $0.03 \pm 0.04$ & 0.02 \\
Contacts & 35 & $0.07 \pm 0.09$ & $0.07 \pm 0.10$ & 0.02 \\
Normals & 39 & $0.04 \pm 0.04$ & $0.04 \pm 0.04$ & 0.03 \\
\hline
\end{tabular}

\footnotetext{
* Mean $\mathrm{OD} \pm$ standard deviation for values using $10 \%$ skimmed milk as the blocking agent.

$\dagger$ Mean OD \pm standard deviation for values using $10 \%$ normal goat serum as the blocking agent.

$\ddagger$ Mean deviation between OD values obtained using $10 \%$ skimmed milk and $10 \%$ normal goat serum.

$\S$ Sera from multibacillary patients.

I Sera from contacts of multibacillary patients.
}

COMPARATIVE ABSORBANCE READINGS OBTAINED USING $10 \%$ SM AND $10 \%$ NGS

A field evaluation using $10 \% \mathrm{SM}$ as a blocking agent was conducted in Cebu, Philippines. Four different samples representing three brands of powdered skimmed milk were purchased and used during the course of this study. A total of 548 serum samples were analysed for IgM antibody against the natural disaccharide, ND-O-BSA. The group consisted of: 39 normals, 137 paucibacillary cases, 156 new contacts, 95 old contacts, 78 new multibacillary cases and 48 old multibacillary cases. No difference in value of positive and negative controls could be found with the use of skimmed milk from different brands. One hundred and thirty-seven samples were chosen at random, and their absorbance readings compared with those obtained in Hawaii using $10 \%$ NGS as the blocking agent. Results of the evaluation are compared in Table 4. The mean deviation in absorbance values obtained using $10 \%$ NGS and $10 \%$ SM are as follows: multibacillary, 0.03 ; paucibacillary, 0.02; contacts (new and old), 0.02; normals, $0 \cdot 03$.

\section{Discussion}

In the ELISA procedure, one of the first requirements is the blocking of plates to prevent nonspecific binding of serum antibodies and enzyme reagents. Failure to sufficiently block available binding sites leads to increased absorbance (A) readings and therefore, false positive reactions of supposedly negative sera. An effective blocking agent is thus of utmost importance. For some countries, the efficacy of a blocking agent is not the only criterion needed to successf ully apply the ELISA technology. Several laboratories that use this technology in their research, are still being hampered by costly reagents, primarily blocking agents that also require special attention with shipping and handling. To accelerate the process of transf erring this valuable technology to these regions therefore, requires blocking agents that are not only very effective but also affordable and easily available.

Judging from the values of both Tables 1 and 2, we find 10\% SM to be the most effective blocking agent, giving a lower range for absorbance readings. The other blocking agents, $10 \%$ NGS (normal goat serum) and 10\% EAC (egg albumin, crude) could also be considered as effective blocking agents since their overall absorbance range are not too far off from those of $10 \% \mathrm{SM}$. However, they both have their drawbacks: both require cold temperatures for storage $(10 \% \mathrm{NGS}$ at $-20^{\circ} \mathrm{C}, 10 \%$ EAC requires $0-4^{\circ} \mathrm{C}$ ). This cold temperature requirement becomes a problem when they need to be shipped to some countries. Some areas do not have efficient delivery services 
available to them that will guarantee frozen or ref rigerated conditions upon arrival of the reagents. Skimmed milk on the other hand is available in $3.2 \mathrm{oz}$ packets that can be stored at room temperature for prolonged periods of time alleviating the problem of inadequate freezer and refrigerator storage space and eliminating cold temperature shipping. It can also be purchased at local grocery stores avoiding the troublesome process and delays associated with ordering from foreign suppliers.

Another favourable aspect of skimmed milk is its simple preparation. All that is required is weighing of the blocking agent and then dissolving in PBSTW20. It dissolves quite readily, unlike $10 \%$ EAC which requires $30 \mathrm{~min}$ of constant stirring with a magnetic stir bar and filtering to remove any undissolved sticky aggregates.

Economically, skimmed milk is comparatively very inexepensive, with a cost of 5 cents per 100 $\mathrm{ml}$ for a $10 \%$ preparation. One litre of a $10 \%$ solution will block four plates, dilute 152 samples plus 4 controls at $1: 500$ ( $10 \mu \mathrm{l}$ of sample and $4990 \mu$ ldiluent $)$, and dilute $20 \mathrm{ml}$ of conjugate at $1: 6000$ for a total cost of 50 cents.

Fresh egg albumin, a cheaper and easily available blocking agent has been used by one of us at the National Institute of Dermatology in Nanjing, China. It blocks well compared to others and could possibly be used as an alternative, however, we find its preparation to be quite tedious, requiring careful aspiration of the white portion of the egg and a subsequent filtration to remove coagulated aggregates.

In some countries, skimmed milk or nonfat dried milk (BLOTTO) is already used by researchers in technologies other than microtiter ELISA, for example: recombinant DNA and Western blot techniques. ${ }^{6}$ Although bovine products such as skimmed milk and bovine albumin as well as normal goat serum may contain cross-reactive immunoglobulins, these reagents did not adversely interfere with the ELISA system we tested.

An exhaustive evaluation using skimmed milk as the blocking agent was conducted at LWM Cebu, Philippines. We compared the values obtained in Cebu with those obtained using $10 \%$ NGS here in Hawaii. The OD values were very much comparable with a mean deviation of 0.02 for paucibacillary and contact samples, and 0.03 for multibacillary and normal samples. As can be seen in Table 4 there is no significant variation in the mean and standard deviation between the OD values obtained using the two blocking agents. No significant deviation was observed in the OD values when we compared results obtained with the skimmed milk used in Cebu and skimmed milk used in Hawaii.

We recommend the use of skimmed milk as an alternative blocking agent for leprosy ELISA because it blocks very effectively, is simple to prepare, does not require cold temperatures for shipping and storage, is more easily available than other conventional blocking agents and is quite inexpensive to use. It is relatively pure since it is a pasteurized product and is screened by the dairy industry for bacterial contamination.

Since initial presentation of this work at the group meeting sponsored by the World Health Organization, Western Pacific Region held in Manila, June 1986, 10\% SM/PBS Tween 20 blocking system has been used successfully in Manila, Philippines and Bangkok, Thailand. ${ }^{7,8}$

\section{Acknowledgments}

This research was supported by the Leonard Wood Memorial American Leprosy Foundation, Rockville; National Institute of Allergy and Infectious Diseases Grant \#R22 A1 24154; Pacific Health Research Institute, Honolulu; and the University of Hawaii Office of Research Administration. We thank the Philippine Government Ministry of Health for their cooperation in the collection of sera used in this study. We also thank Ms Manuela Luisa Parrilla for her excellent technical assistance at Leonard Wood Memorial Research Laboratory, Cebu, Philippines. 


\section{References}

1 Abe M, Saito T, Mathur SK. Early serodiagnosis of leprosy by indirect immunofluorescence. Lepr India, 1976; 48: $272-6$.

2 Report of the Sixth Meeting of the Scientific Working Group on the Immunology of Leprosy. Geneva, 1982; 15.

3 Futian Li. Shanghai Zun Yi Hospital, Shanghai, China. (Personal communication) 1986.

${ }^{4}$ Ridley DS, Jopling WH. Classification of leprosy according to immunity: a fivegroup system. Int J Lepr, 1966; 34: $255-73$

5 Chatterjee D, Cho SN, Brennan JP, Aspinall GO. Chemical Synthesis and Seroreactivity of the 3,6-di-OMethyl-beta-D-Glucopyranosyl (1-> 4-0-)2,3 Dimethyl Rhamnopyronside (1->9) Oxynonanoyl-Bovine Serum Albumin: the Leprosy Specific Natural Dissacharide-Octal Neoglycoprotein. Carbohydrate J, 1986; 156: $39-56$.

${ }^{6}$ Douglas JT, Naka OS, Lee JW. Development of an ELISA for detection of antibody in leprosy. Int J Lep, 1983; 52: 19-25.

7 Johnson DA, Gautsch JW, Sportsman JR, Elder JH. Improved technique utilizing non-fat dry milk for analysis of proteins and nucleic acids transferred to nitrocellulose. Gene Anal Tech, 1984; 1: 3-8.

${ }^{8}$ Chan G, Roscom R. Ministry of Health, Philippines. (Personal communication) 1986.

9 Bencha P. Mahidol University, Thailand. (Personal communication) 1987.

\section{TEACHING MATERIALS AND SERVICES}

\section{English Language Book Society (ELBS); catalogue}

The ELBS Student Editions are low-priced editions of British publishers' books, chosen by an advisory committee for their value to students in developing countries. They are priced at between one third and a half of the price of the cheapest publishers' editions and are made available to students by a subsidy from the British Government in approximately 80 countries:

Africa Benin, Botswana, Burundi, Cameroon, Chad, Congo (Brazzaville), Djibouti, Ethiopia, Gabon, The Gambia, Ghana, Guinea, Ivory Coast, Kenya, Lesotho, Liberia, Madagascar, Malawi, Mauritania, Mauritius, Niger, Nigeria, Rwanda, Senegal, Seychelles, Sierra Leone, Somalia, Swaziland, Tanzania, Togo, Uganda, Upper Volta, Zaire, Zambia, Zimbabwe.

Asia Bangladesh, Brunei, Burma, Hong Kong, India, Indonesia, Laos, The Maldives, Malaysia, Nepal, Pakistan, Singapore, Sri Lanka, Thailand.

Pacific Fiji, Kiribati, Papua New Guinea, Solomon Islands, Tonga, Tavalu, Vanuatu, Western Samoa.

West Indies and Atlantic Antigua, Bahamas, Barbados, Belize, British Virgin Islands, Cayman Islands, Dominica, Guyana, Jamaica, Monserrat, St Kitts-Nevis, Anguilla, St Lucia, St Vincent, Surinam, Trinidad and Tobago, Turks and Caicos Islands, St Helena.

Middle-East Egypt, Jordan, Sudan.

The main subjects covered are: social sciences, pure sciences and applied sciences. Under medical sciences (p 25) and medical microbiology (pp 27/28) alone, there are numerous entries of considerable interest. Many important books, including several on laboratory work in developing countries, etc., are either available or under development or revision. In countries where there is a British Council Library, an exhibition set of these ELBS books is usually kept for consultation. Books cannot be supplied free: they should be purchased direct from local booksellers. Source: ELBS, The British Council, 11 Portland Place, London W1N 4EJ. 


\section{XIIIth International Leprosy Congress, 11-17 September, 1988, The Hague, The Netherlands}

Full details of the sessions have already been printed in this journal; see Number 1, 58, 1986.

The Congress Location and Hotel Accommodation: The 13th ILA Congress will be held in The Netherlands Congress Centre, The Hague, The Netherlands, from 11-17 September 1988. Hotel accommodation will be provided in several price categories ranging from ca. Dfl. 50,-to Dfl. 250,- and more. Congress Bureau: For all information concerning the congress, please contact the Congress Bureau: QLT Convention Services, Keizersgracht 792, 1017 EC Amsterdam, The Netherlands. Tel. +31 (0)20-26 1372, Tlx. 31578 inter nl att qlt. This Meeting is co-sponsored by the World Health Organization.

XIIth International Congress for Tropical Medicine and Malaria, September 1988 This congress will be held in the International Congress Center RAI in Amsterdam from 18-24 September 1988, immediately after the International Leprosy Congress (above).

Information can be obtained at: Organisatie Bureau, Amsterdam, Europaplein 12, 1078 GZ Amsterdam, The Netherlands. Tel. + 31 (0)20-440807, Tlx. 13499.

\section{Meeting of the International Society of Dermatology, Oxford, September 1988}

A joint meeting of this Society with the International Society of Dermatopathology will take place in Oxford, UK, 4-8 September, 1988. There will be at least two sessions on leprosy, including histopathology, together with exhibits and demonstrations, one of which will come from the Wellcome Institute of Tropical Medicine in London. Further details; Mrs Christine Cherry, Department of Dermatology, the Slade Hospital, Headington, Oxford, OX3 7JH, England.

\section{Mini-leprosy Guide, 1988, National Leprosy Organization, India}

Mr Tare of the Gandhi Memorial Leprosy Foundation, PO Hindinagar, Wardha 442 103, India, has kindly sent a copy of this excellent guide or diary which, as in previous years, contains a great deal of basic information about leprosy. The opening pages (in red print) deal with diagnosis, classification, treatment, etc, and the final pages with sources of further inf ormation, a list of journals on leprosy, together with details of teaching-learning material available from GMLF and other agencies. The inclusion of so much useful information in a diary, which is likely to be in almost daily use by many people, is clearly an excellent idea - and one which might well be copied in French, Spanish, Portugese and some local languages.

\section{Innovations in Medical Education; University of New South Wales}

The latest publication from the School of Medical Education, University of New South Wales, PO Box 1, Kensington NSW 2033, Australia, is entitled 'Implementation and Innovations in Medical Education' (1987). It records the proceedings of an intercountry workshop sponsored by the World Health Organization and held at the WHO Western Pacific Regional Teacher Training Centre for Health Personnel in the above university. The main contents included: the medical curriculum and primary health care; trends in the medical curriculum; case studies in educational innovation; organizational arrangements for curriculum development; planning and managing change; evaluation of educational innovation. One of the annexes gives a list of the participants and their affiliations. This publication is a valuable ref erence source for anyone involved with changes in curricula in medical education (and should in fact also be in the hands of medical school staff even if they are not considering changes). It may also help those who are currently attempting to draft outline curricula or modules for the teaching of leprosy in medical schools.

\section{The Global AIDS Epidemic in 1987-88; WHO}

Press Release WHO/34 of 16 December 1987 gives an excellent account of the present world situation in general terms, including reference to the dramatic increase in the number of countries reporting AIDS during 1987. Another document, WHO Features, Number 114, December 1987, deals with the subject in much greater detail: 'The AIDS pandemic poses serious questions for public health worldwide. What is the state of AIDS in the world today? How does the pandemic affect specific regions? What are the prospects for a vaccine or treatment? What role does WHO play? In an interview with Dr Jonathan Mann, Director of the World Health Organization's Special Programme on AIDS, these and other questions are addressed. It includes also a comprehensive review of activities over the past year as well as recent developments in the global AIDS epidemic.' 